\title{
Heating effects on some quality characteristics of date seed oil
}

\author{
Besbes Souhail ${ }^{1}$, Blecker Christophe ${ }^{3}$, Deroanne Claude $^{3}$, Lognay Georges $^{4}$, Nour-Eddine Drira ${ }^{2}$, Hamadi Attia ${ }^{1}$ \\ ${ }^{1}$ Unité Analyses Alimentaires, Département de biologie, Ecole Nationale d'Ingénieurs de Sfax, Route de Soukra B.P. \\ W., 3038 Sfax, Tunisie. \\ ${ }^{2}$ Laboratoire de biotechnologie végétale, Faculté des Sciences de Sfax, Route de Soukra, 3038 Sfax, Tunisie. \\ ${ }^{3}$ Unité de Technologie des Industries Agro-alimentaires, Faculté Universitaire des Sciences Agronomiques de \\ Gembloux, passage des Déportés 2, 5030 Gembloux, Belgique. \\ ${ }^{4}$ Unité de Chimie Générale et Organique, Faculté Universitaire des Sciences Agronomiques de Gembloux, passage des \\ Déportés 2, 5030 Gembloux, Belgique.
}

\begin{abstract}
Effects of heating on some quality characteristics of date seed oil from two cultivars (Deglet Nour and Allig) has been investigated using an accelerated test in a Rancimat system. Fatty acid, viscosity, absorptivity at 232 and 270 $\mathrm{nm}$, colour and total melting enthalpy of Deglet Nour seed oil were less changed compared to that of Allig seed oil, because the former contained a higher amount of total phenolic compounds ( $526 \mu \mathrm{g} / \mathrm{g}$ against $215 \mu \mathrm{g} / \mathrm{g}$ ) and a lower content of unsaturated fatty acids. Viscosity and absorptivity at $232 \mathrm{~nm}$ and at $270 \mathrm{~nm}$ increased rapidly after reaching the oxidation induction time. Differential scanning calorimetry melting profiles of date seed oils were also changed after heating in the Rancimat. Melting enthalpies seemed to be constant during the initial stages of Rancimat treatment and then reduced after the induction time was reached. The obtained data shows that date seed oils were resistant to thermal treatment during a long period ( $30-40 \mathrm{~h})$. This may indicate that they could bear thermal treatments that could be applied in refining procedures or in culinary treatments such as frying and cooking conditions. We could also expect that they may have a good shelf life.
\end{abstract}

Keywords: Date seed oil - heating - oxidation - quality characteristics.

\section{INTRODUCTION}

The date (Phoenix dactylifera L.) has always played an important part of the economic and social lives of the people of arid and semi arid regions of the world. Tunisia is considered to be one of the date producing countries; the number of these trees is estimated to be over 4 million and around 100,000 tons of dates are produced annually. The fruit of the date palm is composed of a fleshy pericarp and seed.

Date seeds may have extractible high value-added components. Presently, however, very little use is made of these components: they are discarded or used in animal feed. Little research has been undertaken on date palm seeds; this has focused particularly on their chemical composition (Al-Showiman, 1990; Al-Hooti, Sidhu, \& Qabazard, 1998; Devshony, Eteshola, \& Shani, 1992; El-Shurafa, Ahmed, \& Abou-Naji, 1982; Hamada, Ha-shim, \& Sharif, 2002). Date palm seeds are a waste product of many industries based on the technological transformation of date fruits (Al-Hooti, Sidhu, Al-Ota-ibi, Al-Ameeri, \& Qabazard, 1997; Hobani, 1998; Khat-chadourian, Sawaya, Khalil, \& Mashadi, 1983; Youssif, Abou Ali, \& Bou Idreese, 1990; Youssif, Alghamdi, Hamad, \& Mustafa, 1996; Youssif \& Al-Ghamdi, 1999) or on their biological transformation (Abou Zied \& Baghlef, 1983; Abou Zied, Abderrahman, \& Baghlef, 1991; Abou Zied \& Khoja, 1993; Al-Obaidi \& Berry, 1976; Nacib, Nacib, \& Bourdant, 1997; Nacib et al., 1999). Then, a large quantity of date seeds could be easily collected from the date processing industries or from the waste products (represent nearly $30 \%$ of the production in Tunisia) coming either directly from the palm grove or from the gap-conditioning stations.

It is well known that the average weight of date seeds is about 10-15\% of date weight (Almana \& Mahmoud, 1994; Hussein, Alhadrami, \& Khalil, 1998). In Tunisia, the lipid fraction of date seeds could amount to over 1000 tons, assuming a mean proportion of $10 \%$ of seed in date fruits and $10 \%$ oil content of seeds. Some scientists have studied chemical characteristics and fatty acid composition of date seed oil. The chemical characteristics of seed oil from six Libyan date cultivars were as follows: iodine number $\sim 54.8$, saponification value $\sim 207$ and acid value 1.75 (El-Shurafa et al., 1982). The major fatty acid found in date seed oil was oleic acid (Al-Showiman, 1990; Devshony et al., 1992). Fair amounts of lauric acid, myristic acid and palmitic acid ranging between $15.4 \%$ and $23.8 \%$; $7.42 \%$ and $11.8 \%$, $6.96 \%$ and $10.2 \%$ were also observed (Al-Showiman, 1990). In a previous paper, we reported that the oxidative stability of date seed oils was higher than that of most vegetable oils and comparable to that of olive oil (Besbes, Blecker, Deroanne, Drira, \& Attia, 2004). They can also be used in formulation of Sun UV protectors that provide protection against both UV-A and UV-B, which we responsible for cellular damage (Besbes et al., 2004). Regarding their specificities, date seed oils could be used in cosmetic, pharmaceutical and food products (Besbes et al., 2004). 
In our knowledge, the study of thermo-oxidation effects on physico-chemical characteristics of date seed oil has not yet been done. Storage tests, like shelf-life tests or oven tests (at 60 or $100{ }^{\circ} \mathrm{C}$ ) could be used to study physico-chemical changes of edible oils (Nissiotis \& Tasioula-Margari, 2002; Vieira \& Regitano-d'Arce, 2001), but they require some days to give a result. Nissiotis and Tasioula-Margari (2002) indicated that heating at $100{ }^{\circ} \mathrm{C}$ simulates cooking conditions. However, the Rancimat method was the most frequently cited for the determination of the resistance of fat and oil to oxidation (Halbault, Barbé, Arozte-gui, \& De La Torre, 1997). The stability of fatty substances was determined in accelerated and standard controlled conditions with a dry air flow and high temperature. The system allowed automatic evaluation of the oxidation induction time but could be also used to follow physico-chemical characteristics changes during thermal treatment of fats and oils, in well controlled conditions.

The use of date seed oil for industrial applications or for culinary preparations could necessitate its exposure to high temperature such as refining operation, frying, cooking conditions, etc. These thermal treatments could lead to changes in quality characteristics of the oils. The aim of this present work was to study physico-chemical changes of date seed oils during heating. Following heat-induced physico-chemical characteristics changes of date seed oils, we could also indicate until what stage they could bear this treatment.

\section{MATERIALS AND METHODS}

\subsection{Seed material}

The seeds of the two cultivars: Deglet Nour and Allig were directly isolated from $50 \mathrm{~kg}$ of waste date fruit having the same origin (National Institute of Arid Zone Degach, Tunisia) and collected at the "Tamr stage" (full ripeness). The seeds were soaked in water, washed to free them of any adhering date flesh, air-dried and then dried (12 h) at about $50{ }^{\circ} \mathrm{C}$. Date seeds, from each variety, were separately milled in a heavy-duty grinder to pass 1-2 mm screens and then preserved at $-20{ }^{\circ} \mathrm{C}$ until analyses.

\subsection{Lipid extraction and preservation}

Lipid extraction was carried out with SER 148 Solvent Extractor (Velp Scientifica, Europe) equipped with six Soxhlet posts. About $15 \mathrm{~g}$ of powdered date seeds were used for oil extraction, with petroleum ether $40-60{ }^{\circ} \mathrm{C}$ (Merck), in each Soxhlet post (Besbes et al., 2004). The operational conditions were:

- immersion time: 30 min with thimble immersed in boiling solvent,

- washing time: 60 min of reflux washing.

The relative percentage weight of lipids compared with weight of dried seeds was about $10.2 \%$ for Deglet Nour cultivar and about $12.7 \%$ for Allig cultivar (Besbes et al., 2004). The obtained seed oils were drained under a stream of nitrogen and then stored in a freezer $\left(-20^{\circ} \mathrm{C}\right)$ for subsequent analyses.

\subsection{Thermo-oxidation treatment of oil}

Thermo-oxidative treatment was done using a Rancimat 679 apparatus (Metrohm AG, Herison, Switzerland) respecting these conditions: oil samples of $2.5 \mathrm{~g}$, temperature $=100^{\circ} \mathrm{C}$, air flow rate of $15 \mathrm{l} / \mathrm{h}$. After Rancimat treatment (going from 0 to $48 \mathrm{~h}$ ), seed oils were drained under a stream of nitrogen and then stored in a freezer $\left(-20{ }^{\circ} \mathrm{C}\right)$ for subsequent analyses.

\subsection{Analytical methods}

All analytical determination were performed at least in triplicate. Values of different parameters were expressed as the mean $\pm \mathrm{SD}(\tilde{\mathrm{X}} \pm \mathrm{SD})$.

\subsubsection{Fatty acid composition}

Treated and non-treated date seed oils were converted to their corresponding methyl ester using boron trifluoride methanol complex $(14 \% \mathrm{w} / \mathrm{v})$. The mixture was maintained at $100{ }^{\circ} \mathrm{C}$ for $1 \mathrm{~h}$. The reaction was stopped with $0.5 \mathrm{ml}$ of distilled water. Then, the extracted fatty acid methyl esters (FAMEs) were dissolved in heptane for GC analyses.

GC analyses were performed on a Hewlett-Packard 5890 Series II gas chromatograph (H.P. Co., Amsterdam, The Netherlands) equipped with a hydrogen flame ionization detector and a capillary column: HP Inovax cross-linked PEG 
(30 $\mathrm{m} \times 0.32 \mathrm{~mm} \times 0.25 \mu \mathrm{m}$ film). The column temperature was programmed from 180 to $240{ }^{\circ} \mathrm{C}$ at $5^{\circ} \mathrm{C} / \mathrm{min}$ and the injector and detector temperature were set at $250^{\circ} \mathrm{C}$. Nitrogen was the carrier gas. FAMEs were identified by comparison of their retention time with respect to pure standard FAMEs purchased from Sigma and analyzed under the same conditions. Date seed FAMEs were quantified according to their percentage area, obtained by integration of the peaks. The results were expressed as a percentage of individual fatty acids in the lipid fraction.

\subsubsection{Total phenol}

Total phenols in date seed oil were determined colorimetrically at $725 \mathrm{~nm}$ with the Folin-Ciocalteau reagent as previously done by Gutfinger (1981) on virgin olive oil.

\subsubsection{Color}

The CieLab coordinates $\left(\mathrm{L}^{*}, \mathrm{a}^{*}, \mathrm{~b}^{*}\right)$ were directly read with a spectrophotocolorimeter MS/Y-2500 (Hunterlab, Inc., Reston, VA, USA), calibrated with a white tile. Twelve readings were taken on each sample. Difference in color $(\Delta E)$, between the initial and the treated date seed oils, is expressed as follows: $\Delta E=\left[\left(\Delta L^{*}\right)^{2}+\left(\Delta a^{*}\right)^{2}+\left(\Delta b^{*}\right)^{2}\right]^{0.5}$.

\subsubsection{UV - spectrophotometric analyses}

Specific absorptivity at 232 and $270 \mathrm{~nm}$ were calculated from the absorption at the corresponding waves length, with an UV-240 spectrophotometer (Shimmadzu - Corporation, Kyoto, Japan) using a 1\% solution of oil in hexane and a path length of $1 \mathrm{~cm}$.

\subsubsection{Viscosity determination}

Viscosity was followed at $25^{\circ} \mathrm{C}$ with a Stress Tech Rheologica Rheometer (Rheologica Instruments AB, Lund, Sweden) conducted with a steel cone-plate (C40/4) under a constant shear rate of $100 \mathrm{~s}^{-1}$.

\subsubsection{Differential scanning calorimetry (DSC)}

Thermal properties were determined with a differential scanning calorimeter (DSC 2920 Modulated DSC-TA Instruments, Newcastle, DE, USA). Oil $(2 \pm 0.1 \mathrm{mg})$ was weighed in DSC-pan (SFI - aluminium, TA Instrument T11024). The sample was quickly cooled to $-50{ }^{\circ} \mathrm{C}$ with a speed of $15{ }^{\circ} \mathrm{C} / \mathrm{min}$, maintained at this temperature for 15 min, and heated to $90{ }^{\circ} \mathrm{C}$ with a heating speed of $15^{\circ} \mathrm{C} / \mathrm{min}$. The same operation (cooling and heating) was repeated and the DSC thermographs were recorded during the second melting. An empty DSC-pan was used as an inert reference to balance heat capacity of the sample pan. The DSC was calibrated for temperature and heat flow using ecosane $\left(T_{\mathrm{p}}=\right.$ $\left.36.8^{\circ} \mathrm{C}, H=247.7 \mathrm{~J} / \mathrm{g}\right)$ and dodecane $\left(T_{\mathrm{p}}=-9.65^{\circ} \mathrm{C}, H=216.73 \mathrm{~J} / \mathrm{g}\right)$.

\section{RESULTS AND DISCUSSION}

\subsection{Rancimat oxidative stability}

Table 1 shows oxidation induction time and total phenol content of date seed oil. Deglet Nour and Allig seed oil have both a higher oxidation induction time ( $\sim 5$ and $\sim 33 \mathrm{~h}$, respectively). The difference in the oxidation induction period was explained by the Allig seed oil's high level of monounsaturated fatty acids (MUFA) and polyunsaturated fatty acids (PUFA) compared to Deglet Nour seed oil (49.2\% and $21.8 \%$ against $41.5 \%$ and $14.1 \%$, respectively) (Besbes et al., 2004). The same tendency was observed by Salvador, Aranda, Gomez-Alonso, and Fregapane (2001), who revealed a strong negative correlation between linoleic acid and olive oil stability measured by Rancimat. Deglet Nour seed oil also has a higher phenol content $(526 \mu \mathrm{g} / \mathrm{g}$ against $215 \mu \mathrm{g} / \mathrm{g})$ which would contribute, with other antioxidants, to increasing the oxidative stability of edible oils. The contribution of phenolic and ortho-diphenolic compounds in virgin olive oil oxidation stability was the highest compared to that of fatty acid composition, $\alpha$-tochopherols, carotenoids and chlorophylls (Aparicio, Roda, Albi, \& Gutiérrez, 1999). It has been also found that a linear relationship exists between total polyphenol content and oxidative stability of olive oil by Rancimat (Caponio, Alloggio, \& Gomes, 1999; Montedoro et al., 1993; Papadopoulus \& Boskow, 1991; Salvador et al., 2001). 
Table 1. Oxidation induction time ( $h$ ) and total phenols ( $\mathrm{ig} / \mathrm{g}$ ) of seed oil from the two studied date cultivars.

\section{Cultivars}

\begin{tabular}{lll}
\cline { 2 - 3 } & Deglet Nour & Allig \\
\hline Induction time & $44.6 \pm 0.55$ & $33.9 \pm 0.26$ \\
Total phenols & $526 \pm 13.92$ & $215 \pm 9.27$
\end{tabular}

All values given are mean of six determinations.

Date seed oil has a higher phenol content compared to most edible oils except olive oil, which is considered as a rich source of phenolic compounds in the Mediterranean diet. For example, The total phenolic content in olive oil, measured also by Folin-Ciocalteau method, has been shown to range from 19 to $380 \mathrm{ig} / \mathrm{g}$ (Salvador et al., 2001) and from 124 to $516 \mathrm{ig} / \mathrm{g}$ (Nissiotis \& Tasio-ula-Margari, 2002). This may explain the fact that date seed oil presents comparable oxidation induction times to virgin olive oil (Besbes et al., 2004). Date seed oil, especially extracted from Deglet Nour cultivar, could be considered as a potential source of natural phenolic compounds. In addition to their contribution to the resistance of oil to oxidative rancidity and their participation in confering specific flavor to oil (Caponio et al., 1999), it is worthy mention that some authors report that phenols could have a positive effect in the prevention of coronary heart disease and cancer (Owen et al., 2000; Tuck \& Hayball, 2002).

\subsection{Thermo-oxidation effects on quality characteristics}

Some indicators of quality such as fatty acid composition, viscosity, absorptivity at 232 and $270 \mathrm{~nm}$, color and DSC thermal properties were studied in order to study the effect of thermo-oxidation on date seed oil behaviour.

\subsubsection{Fatty acids composition}

Table 2 shows the effect of Rancimat treatment $\left(100^{\circ} \mathrm{C}, 15 \mathrm{l} / \mathrm{h}, 48 \mathrm{~h}\right)$ on the average fatty acid composition of date seed oils from Deglet Nour and Allig cultivars.

Non-treated (NT) seed oils were characterized by the presence of five major fatty acids $\left(\mathrm{C}_{18: 1}, \mathrm{C}_{18: 2}, \mathrm{C}_{16: 0}, \mathrm{C}_{14: 0}\right.$ and $\mathrm{C}_{12: 0}$ ). Oleic fatty acid was always the major fatty acid found: its relative percentage ranged from $41.3 \%$ for Deglet Nour seed oil to $47.7 \%$ for Allig seed oil (Besbes et al., 2004). These results are in agreement with those previously reported (Al-Hooti et al., 1998; Al-Showiman, 1990; Devshony et al., 1992). Deglet Nour seed oil showed higher saturated fatty acid content (SAFA -44.3\%) than Allig seed oil (SAFA -26.3\%). However, Allig seed oil contained higher amounts of linoleic and oleic acids. Generally, oils with higher proportions of unsaturated fatty acids are more prone to oxidation than those containing lesser amounts (Tan \& Che Man, 1999)

Rancimat treatment causes a decrease in the relative percentages of the unsaturated fatty acids and an increase of the relative percentages of the saturated fatty acids (Liu \& White, 1992). Thus, decrease in MUFA and PUFA percentages across 48 h of heating were, respectively, about $15.1 \%$ and $74.8 \%$ for Deglet Nour seed oil and about $40.8 \%$ and $89.9 \%$ for Allig seed oil. Similarly, the increase in SAFA in Allig seed oil was lower.

Decreases in MUFA (essentially $\mathrm{C}_{18: 1}$ ) was lower than decreases in PUFA (essentially $\mathrm{C}_{18: 2}$ ) because lino-leic acid is more susceptible to oxidation. The latter is usually used as an indicator of the extent of oil deterioration.

Decreases in MUFA and PUFA for Allig seed oil, reflecting the oxidation degradation, were more important due to:

- $\quad$ its higher initial content in $\mathrm{C}_{18: 1}$ and $\mathrm{C}_{18: 2}$;

- $\quad$ its lower phenolic content (215 ig/g against $528 \mathrm{ig} / \mathrm{g})$ (Table 1). 
Table 2. Fatty acid composition (\%) of date seeds oils.

\begin{tabular}{|c|c|c|c|c|}
\hline \multirow[t]{2}{*}{ Fatty acid } & \multicolumn{2}{|l|}{ Deglet Nour } & \multicolumn{2}{|l|}{ Allig } \\
\hline & $\mathbf{N T}^{\mathbf{a}}$ & $\mathbf{T}$ & $\mathbf{N T}^{\mathbf{a}}$ & $\mathbf{T}$ \\
\hline Capric $\mathrm{C}_{10: 0}$ & $0.08 \pm 0.13$ & $0.68 \pm 0.05$ & $0.07 \pm 0.01$ & $0.79 \pm 0.13$ \\
\hline Lauric $\mathrm{C}^{12: 0}$ & $17.8 \pm 0.36$ & $31.7 \pm 1.39$ & $5.81 \pm 0.25$ & $34.2 \pm 2.07$ \\
\hline Myristic $C_{14: 0}$ & $9.84 \pm 0.09$ & $14.0 \pm 0.30$ & $3.12 \pm 0.06$ & $15.7 \pm 0.62$ \\
\hline Myristoleic $\mathrm{C}_{14: 1}$ & $0.09 \pm 0.15$ & $0.53 \pm 0.06$ & $0.04 \pm 0.03$ & $2.37 \pm 0.20$ \\
\hline Palmitic $\mathrm{C}_{16: 0}$ & $10.9 \pm 0.17$ & $10.6 \pm 0.10$ & $15.0 \pm 0.31$ & $13.8 \pm 0.28$ \\
\hline Palmitoleic $\mathrm{C}_{16: 1}$ & $0.11 \pm 0.19$ & $0.21 \pm 0.04$ & $1.52 \pm 0.01$ & $0.46 \pm 0.08$ \\
\hline Stearic $\mathrm{C}_{18: 0}$ & $5.67 \pm 0.20$ & $3.88 \pm 0.10$ & $3.00 \pm 0.03$ & $4.24 \pm 1.05$ \\
\hline Oleic $\mathrm{C}_{18: 1}$ & $41.3 \pm 0.76$ & $34.5 \pm 1.86$ & $47.7 \pm 1.11$ & $26.3 \pm 1.45$ \\
\hline Linoleic $\mathrm{C}_{18: 2}$ & $12.4 \pm 0.15$ & $3.28 \pm 0.25$ & $21.0 \pm 0.29$ & $0.27 \pm 0.17$ \\
\hline Linolenic $\mathrm{C}_{18: 3}$ & $1.68 \pm 0.71$ & $0.27 \pm 0.06$ & $0.81 \pm 0.38$ & $1.92 \pm 0.85$ \\
\hline SAFA & $44.3 \pm 0.96$ & $60.8 \pm 1.96$ & $27.0 \pm 0.66$ & $68.3 \pm 4.16$ \\
\hline MUFA & $41.5 \pm 1.10$ & $35.2 \pm 1.96$ & $49.2 \pm 1.15$ & $29.2 \pm 1.73$ \\
\hline PUFA & $14.1 \pm 1.62$ & $3.55 \pm 0.32$ & $21.8 \pm 0.68$ & $2.19 \pm 1.03$ \\
\hline
\end{tabular}

All values given are means of three determinations. NT, non-treated oil; T, oil treated in Rancimat at $100{ }^{\circ} \mathrm{C}$ for $48 \mathrm{~h}$ with an air flow of 15 $1 / \mathrm{h}$.

a According to Besbes et al. (2004).

\subsubsection{Colour}

In this study, we compared $L^{*}, a^{*}$ and $b^{*}$ parameters of Deglet Nour and Allig seed oils in their initial state with that after treatment in the Rancimat apparatus $\left(100{ }^{\circ} \mathrm{C}, 15 \mathrm{l} / \mathrm{h}, 48 \mathrm{~h}\right)$ (Table 3). It is interesting to note that date seed oil showed a higher $b^{*}$ than other vegetable oils studied by Hsu and Yu (2002). Then, date seed oils were more yellowcolored than palm oil, soybean oil, sunflower oil, olive oil and corn oil studied by these authors. This supports the presence of more yellow pigment, such as carotenoids, in date seeds oils as shown by Besbes et al. (2004).

Table 3 shows that Rancimat treatment gives a considerable increase in $L^{*}$ and a decrease in $a^{*}$ and $b^{*}$ parameters. Difference in color between non-treated and treated seed oil (DE) was slightly higher for Allig cultivar (55.3\% against $51.2 \%$ ), which is more sensitive to oxidation due to its higher relative percentage of PUFA and MUFA and its lower total phenolic content. This color change was essentially marked by the high loss of yellow color and then that of yellow pigments, essentially $\beta$-carotenes, beyond the oxidation induction time. Ndjouenkeu and Ngassoum (2002) showed that heating during frying lead to bleaching of palm oils caused by destruction of carotenoids responsible for their color.

\subsubsection{Viscosity}

The curves of the viscosity against time are presented in Fig. 1(a). It is worth noting that Deglet Nour seed oil initial viscosity (20 $\mathrm{mPa} \mathrm{s}$ ) was lower than that of most vegetable oils (mean value $\sim 50-100 \mathrm{mPa} \mathrm{s}$ ) and similar to that of raspberry seed oil (26 mPa s) studied by Oomah, Ladet, Godfrey, Liang, and Girard (2000). The initial viscosity of Deglet Nour seed oil was lower than that of Allig seed oil (20 mPa s against $40 \mathrm{mPa} \mathrm{s})$, in spite of the fact that this latter contained more UFA content. This difference is likely to be due to Deglet Nour seed oil's high medium- and short-chain 
fatty acids content (Besbes et al., 2004). An obvious trend in relationship between fatty acid chain length and viscosity was observed (Gustone, Harwood, \& Padley, 1986; Geller \& Goodrum, 2000).

Between 0 and 15 h, Deglet Nour seed oil showed a low increase in viscosity, which reached that of Allig seed oil after $15 \mathrm{~h}$ in the Rancimat. Then, viscosity remains practically constant and finally increases considerably at $48 \mathrm{~h}$, i.e., after the corresponding oxidation induction time was reached (- $44 \mathrm{~h})$. However, Allig seed oil viscosity remain practically constant between $0 \mathrm{~h}$ and the corresponding Rancimat induction time $(-33 \mathrm{~h})$ and increase considerably at 37 and $44 \mathrm{~h}$.

The phase characterized by a low increase in viscosity (for Deglet Nour seed oil), was probably due to hydroperoxides formation. This phase seems to also exist for Allig cultivar, but occurs earlier i.e., during Soxhlet extraction of Allig seed oil, which was more sensitive to oxidation. This hypothesis may also explain the higher initial viscosity of Allig seed oil.

After 37 and $48 \mathrm{~h}$ in the Rancimat, Deglet Nour seed oil showed lower viscosity values because it was more resistant to oxidation, following its lower UFA content and its higher amount of total phenolic compounds. It is known that viscosity decreases when molecular weight decreases. The increase in oil viscosity beyond the Rancimat oxidation induction time was attributed to polymerisation and formation of high molecular weight compounds including carboncarbon and carbon-oxygen-carbon bridges between fatty acids (Stevenson, Vaisey-Genser, \& Eskin, 1984). The increase of the viscosity during heating correlated well with formation of polymers (Bracco, Dieffenbacher, \& Kolarovic, 1981).

\subsubsection{Absorptivity at 232 and $270 \mathrm{~nm}$}

Absorptivity in the UV range could be a good tool for the analysis of oxidized oils. The formation of hydroperoxides is coincidental with conjugation of double bonds in polyunsaturated fatty acids, measured by absorptivity in the UV spectrum (Shahidi \& Wanasundra, 1997).

Fig. 1(a) and (b) illustrates the evolution of the absorptivity at 232 and at $270 \mathrm{~nm}$, respectively, over the time range 0-48 $\mathrm{h}$ in the Rancimat $\left(100{ }^{\circ} \mathrm{C}, 15 \mathrm{l} / \mathrm{h}\right)$. Absorptivity at $232 \mathrm{~nm}$ of Deglet Nour and Allig seed oils evolves in the same way as viscosity (Section 3.2.3). Compared to Deglet Nour Seed oil, Allig seed showed a higher initial absorptivity at 232 $\mathrm{nm}$ that could be explained by its higher sensitivity to heating during the extraction procedure leading to higher content of oxidation primary products.

Table 3. CieLab coordinates $\left(L^{*}, a^{*}, b^{*}\right)$ of date seeds oils.

\begin{tabular}{llllll}
\hline Colour parameters & \multicolumn{2}{l}{ Deglet Nour } & & Allig \\
\cline { 2 - 3 } \cline { 5 - 6 } & NT & T & & NT & T \\
\hline$L^{*}$ & $65.5 \pm 0.30$ & $69.8 \pm 0.21$ & & $55.3 \pm 0.30$ & $71.4 \pm 0.25$ \\
$a^{*}$ & $-0.82 \pm 0.12$ & $-1.55 \pm 0.02$ & & $2.84 \pm 0.18$ & $-2.18 \pm 0.04$ \\
$b^{*}$ & $56.4 \pm 0.67$ & $5.30 \pm 0.09$ & & $59.4 \pm 0.48$ & $6.74 \pm 0.16$ \\
$\Delta E^{*}$ & $51.3 \pm 0.57$ & $55.3 \pm 0.31$ & &
\end{tabular}

All values given are means of 12 determinations. NT, non-treated oil; T, oil treated in Rancimat at $100{ }^{\circ} \mathrm{C}$ for $48 \mathrm{~h}$ with an air flow of $15 \mathrm{l} / \mathrm{h}$.

Absorptivity of Allig seed oil at $232 \mathrm{~nm}$ showed no significant change during the induction period in the Rancimat. However, values increased after the oxidation induction time $(\sim 33 \mathrm{~h})$ due to the increased formation of conjugated dienes. Absorptivity at $232 \mathrm{~nm}$ of Deglet Nour seed oil increased and reached that of Allig seed oil after $\sim 15 \mathrm{~h}$ in Rancimat, and then it remained practically constant. It finally increased considerably after $48 \mathrm{~h}$ in the Rancimat.

The primary products of oxidation are not stable under heating and then their degradation could promote the formation of secondary product of oxidation that absorb at about $270 \mathrm{~nm}$ (Vieira \& Regitano-d'Arce, 2001). Fig. 1(c) shows that specific extinction at $270 \mathrm{~nm}$ does not practically change during $30 \mathrm{~h}$. It can be seen clearly that secondary compounds of oxidation were not detected before reaching the oxidation induction time for the two studied cultivars. This could also confirm that date seed oils have a good resistance against heating. 
Fig. 1. Changes in viscosity (a) and in absorbtivity at $232 \mathrm{~nm}(\mathrm{~b})$ and at $270 \mathrm{~nm}$ (c) during Rancimat treatment of date seed oils. (口) Deglet Nour, (ロ) Allig.
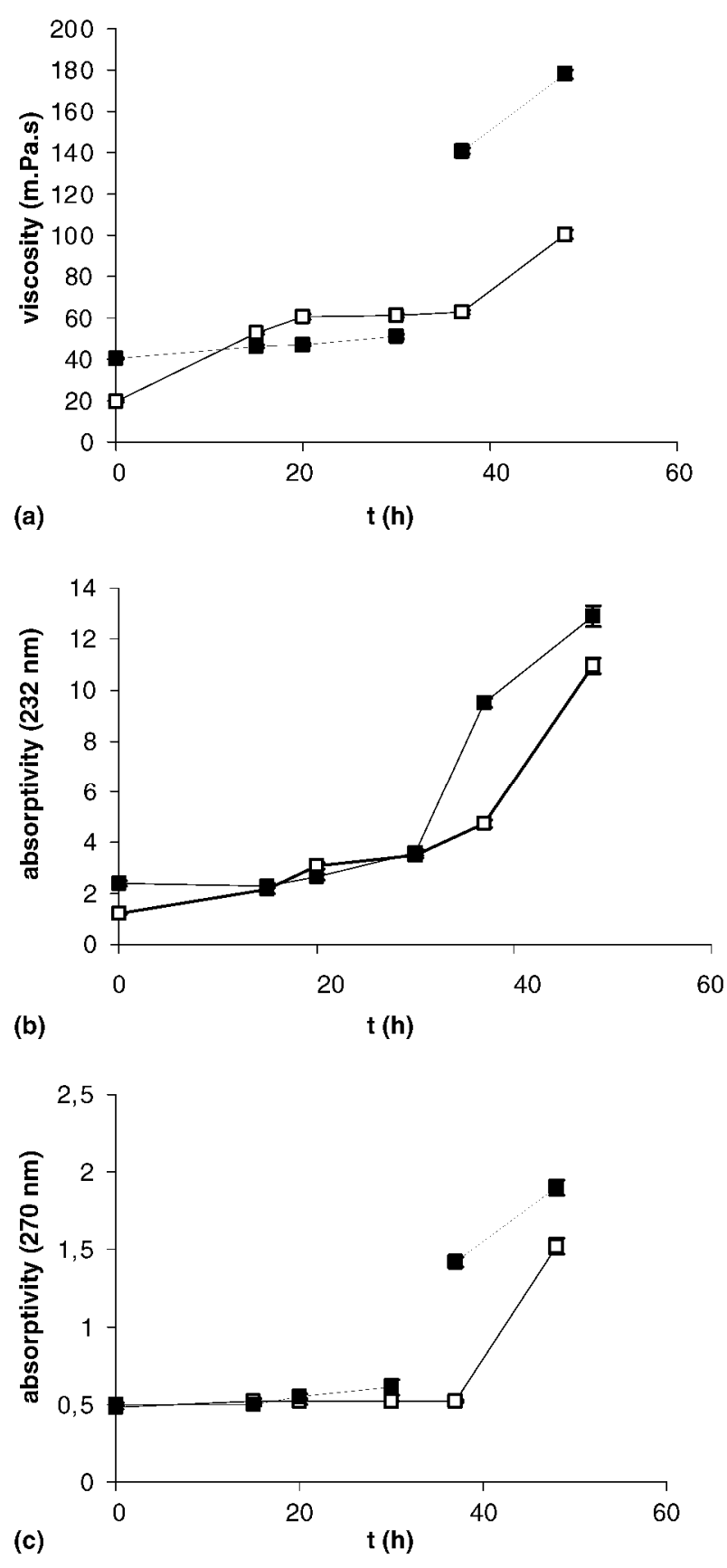

\subsubsection{Thermal behaviour}

The DSC melting curves of date seed oils during heating in the Rancimat are presented in Fig. 2. At the initial time, Deglet Nour and Allig seed oils showed a simple thermogram with a single peak (Besbes et al., 2004). Rancimat treatment caused some modifications of their thermal properties. In fact, for both date seed oils, a high temperature melting peak (HTMP) appeared after the corresponding induction period. Then, the HTMP disappeared. This was clearly shown for Allig seed oil which was more prone to oxidation. 
Fig. 2. Melting thermograms of date seed oil samples with different Rancimat treatment time $(0-48 \mathrm{~h})$. (a) Deglet Nour, (b) Allig, * according to Besbes et al. (2004).
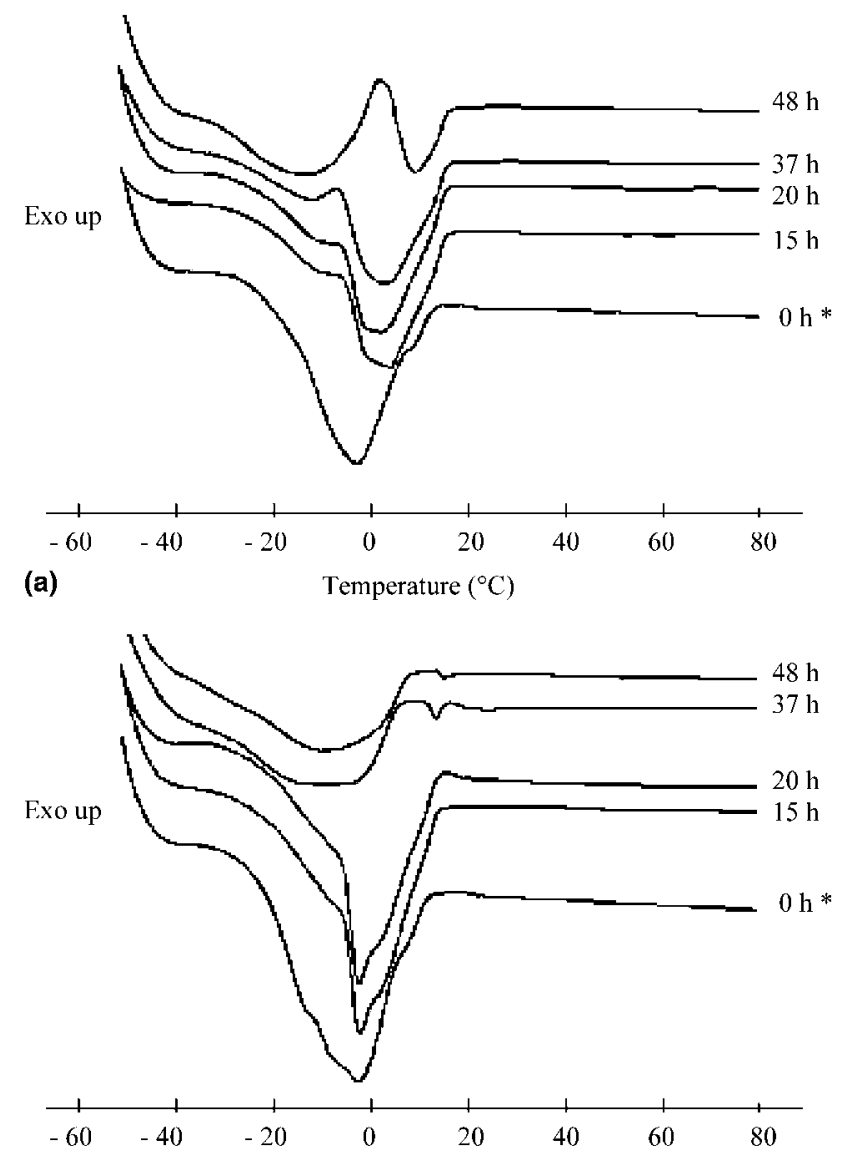

Thus, after the induction period, date seed oil thermograms presented two distinct peaks: a low temperature melting peak (LTMP) and a high temperature melting peak (HTMP). This latter peak was more and more differentiated as the Rancimat treatment time increased. The presence of two distinct peaks may be due to the appearance of a second polymorphic form. This hypothesis is supported by the fact that the oxidized product extracted from heated sunflower oil did not show any thermal transitions in the selected temperature range (Gloria \& Aguilera, 1998). In microwave heated oil, the oxidation products such as polar compounds, hydroperoxydes, aldehydes, dimers and polymers may disturb the rearrangement of different polymorphic form in oils (Tan, Che Man, Jinap, \& Yussof, 2002).

It is worthy to note that the total melting enthalpy was less changed during the induction period (Table 4). As the heating duration goes beyond the oxidation induction time, the total melting enthalpy decreased. The same trends were observed for viscosity and absorbtivity. The final melting enthalpy (after $48 \mathrm{~h}$ ) was lower for Allig cultivar, confirming its higher oxidation sensitivity. In their study of corn oil, palm olein and soybean oil, Tan and Che Man (1999) reported that as the time of heating (at $180^{\circ} \mathrm{C}$ ) increased, crystallization enthalpy decreased dramatically. Changes in thermal properties of heated oil may be attributed to the disappearance of unsaturated triglycerides and the formation of oxidation products (Tan \& Che Man, 1999).

It has been also reported that the formation of oxidation products that do not crystallise in the scanning temperature range was responsible for the reduction in enthalpy of crystallisation with frying time (Gloria \& Aguilera, 1998). The reduction in the enthalpy of crystallisation with frying time was attributed to the formation of degradation products that do not crystallize in the scanning temperature interval. Consequently, the decrease in melting enthalpy observed for date seed oil (Table 4) may be explained by the progressive disappearance of triglycerides groups and the formation of degradation products having a melting domain lower than the scanning temperature range. 
Table 4. Melting enthalpies $(\mathrm{J} / \mathrm{g})$ of date seed oil samples with different Rancimat treatment time ${ }^{a}$.

\begin{tabular}{lll}
\hline Time (h) & Melting enthalpies $(\mathbf{J} / \mathbf{g})$ & Allig \\
\cline { 2 - 3 } & Deglet Nour & $71.9 \pm 0.08$ \\
\hline $0^{\mathrm{a}}$ & $67.5 \pm 0.72$ & $69.0 \pm 1.17$ \\
15 & $64.0 \pm 0.52$ & $59.3 \pm 2.12$ \\
20 & $63.8 \pm 1.78$ & $51.4 \pm 1.45$ \\
48 & $53.7 \pm 2.66$ & $39.8 \pm 1.13$ \\
\hline
\end{tabular}

All values given are the mean of three determinations.

a According to Besbes et al. (2004).

\section{CONCLUSIONS}

The two studied date seed oils presented high oxidation stability and a considerable total phenol contents. Results show that both date seed oils studied could resist thermal treatments that may be applied during frying, cooking conditions or during refining processes. Date seed oils were resistant to thermal treatment during a long period $(\sim 30-40 \mathrm{~h})$ regarding the high stability of some of their quality parameters. So, we could predict that they may have a good shelf-life and then could be stored safely during a long period. This hypothesis will be supported by the study of the behaviour of date seeds oils during storage at ambient temperature.

\section{Acknowledgement}

Authors thank Mr. Hammami Mohamed, responsible for U.S.C.R. spectrometry, for chromatographic analysis.

\section{References}

Abou Zied, A. A., \& Baghlef, A. O. (1983). Utilization of date seeds and cheese whey in production of citric acid by Candida lipolytica. Agricultural Wastes, 8, 131-142.

Abou Zied, A. A., Abderrahman, N., \& Baghlef, A. O. (1991). The formation of oxytetracycline in date-coat medium. Bioresource Technology, 37, 179-184.

Abou Zied, A. A., \& Khoja, S. M. (1993). Utilization of dates in the fermentative formation of citric acid by Candida lipolytica. Zentral Microbiology, $148,213-221$.

Almana, H. A., \& Mahmoud, R. M. (1994). Palm date seed as an alternative source of dietary fiber in Saudi bread. Ecology of Food and Nutrition, 32, 261-270.

Al-Hooti, S., Sidhu, J. S., Al-Otaibi, J., Al-Ameeri, H., \& Qabazard, H. (1997). Processing quality of important date cultivars grown in the United Arab Emirates for jam, butter and dates-in-syrup. Advanve in Food Science, 19, 35-40.

Al-Hooti, S., Sidhu, J. S., \& Qabazard, H. (1998). Chemical composition of seeds date fruit cultivars of United Arab Emirates. Journal of Food Science and Technology, 35, 44-46.

Al-Obaidi, Z. S., \& Berry, D. R. (1976). Saling up of citric acid fermentation using fermenters. Date Palm Journal, 2, $19-33$.

Al-Showiman, S. S. (1990). Chemical composition of date palm seeds (Phoenix dactylifera L.) in Saudi Arabia. Journal of the Chemical Society, 12, 15-24.

Aparicio, R., Roda, L., Albi, M. A., \& Gutiérrez, F. (1999). Effect of various compounds on virgin olive oil stability measured by Rancimat. Journal of Agricultural Food Chemistry, 47, 4150-U55.

Besbes, S., Blecker, C., Deroanne, C., Drira, N. E., \& Attia, H. (2004). Date seeds: Chemical composition and characteristic profiles of the lipid fraction. Food Chemistry, 84, 577-584.

Bracco, U., Dieffenbacher, A., \& Kolarovic, L. (1981). Frying performance of palm oil liquid fraction. Journal of American Oil Chemists Society, 58, 6-12.

Caponio, F., Alloggio, V., \& Gomes, T. (1999). Phenolic compounds of virgin olive oil: Influence of paste preparation techniques. Food Chemistry, 64, 203-209.

Devshony, S., Eteshola, A., \& Shani, A. (1992). Characterisation and some potential application of date palm (Phoenix dactylifera L.) seeds and seeds oil. Journal of American Oil Chemists Society, 69, 595-597.

El-Shurafa, M. Y., Ahmed, H. S., \& Abou-Naji, S. E. (1982). Organic and inorganic constituent of dates palm pit (seeds). Journal of Date Palm, 2, 275-284.

Geller, D. P., \& Goodrum, J. W. (2000). Rheology of vegetable oil analogs and triglycerides. Journal of American Oil Chemist's Society, 77, 111-114. 
Published in: Food chemistry (2005), vol. 91, pp. 469-476

Statut: Postprint (Author's version)

Gloria, H., \& Aguilera, J. M. (1998). Assessment of the quality of heated oils by differential scanning calorimetry. Journal of Agricultural Food Chemistry, 46, 1363-1368.

Gustone, F. D., Harwood, J. L., \& Padley, F. B. (Eds.). (1986). The lipid handbook (pp. 81). London: Chapman \& Hall. Gutfinger, T. (1981). Polyphenols in olive virgin oils. Journal of American Oil Chemists Society, 58, 966-968.

Halbault, L., Barbé, C., Aroztegui, M., \& De La Torre, C. (1997). Oxidative stability of semi-solid excipient mixtures with corn oil and its implication in the degradation of vitamin A. International Journal of Pharmaceutics, 147, 31-41.

Hamada, J. S., Hashim, I. B., \& Sharif, A. F. (2002). Preliminary analysis and potential uses of date pits in foods. Food Chemistry, 76, $135-137$.

Hobani, A. I. (1998). Rheological behaviour of date-water concentrates. Journal of Food Engineering, 36, $349-357$.

Hsu, S. Y., \& Yu, S. H. (2002). Comparisons on 11 plant oil fat substitutes for low-fat kung-wans. Journal of Food Engineering, 51, $215-220$.

Hussein, A. S., Alhadrami, G. A., \& Khalil, Y. H. (1998). The use of dates and date pits in broiler starter and finisher diets. Bioresource Technology, 66, 219-223.

Khatchadourian, H. A., Sawaya, W. N., Khalil, J., \& Mashadi, A. S. (1983). Processing of five major Saudi Arabian date varieties into Dates butter and dates in syrup. Date Palm Journal, 1, 103-119.

Liu, H. R., \& White, P. J. (1992). Oxydative stability of soybean oils with altered fatty acid compositions. Journal of American Oil Chemists Society, 53, 528-532.

Montedoro, G., Servilli, M., Baldioli, M., Selvaggini, R., Miniati, E., \& Macchioni, A. (1993). Simple and hydrolyzable compounds in virgin olive oil. Spectroscopic characterizations of the secoiridoid derivatives. Journal Agricultural Food Chemistry, 41, $2228-2234$.

Nacib, N., Nacib, A., \& Bourdant, J. (1997). Use of waste products in the fermentative formation of Baker's yeast biomass by Saccharomyces cervisiae. Bioresource Technology, 60, 67-71.

Nacib, N., Nacib, A., Mostefa, G., Larbi, L., Adimi, L., Remmal, M., et al. (1999). Use of date products in production of thermophilic dairy starters strain Streptococcus thermophilus. Bioresource Technology, 67, 291-295.

Ndjouenkeu, R., \& Ngassoum, M. (2002). Etude comparative de la valeur en friture de quelques huiles végétales. Journal of Food Engineering, 52, 121-125.

Nissiotis, M., \& Tasioula-Margari, M. (2002). Changes in antioxydant concentration of virgin olive oil during thermal oxidation. Food Chemistry, 77, 371-376.

Oomah, B. D., Ladet, S., Godfrey, D. V., Liang, J., \& Girard, B. (2000). Characteristics of raspberry (Rubus idaeus L.) seed oil. Food Chemistry, 69, 187-193.

Owen, R. W., Giacosa, A., Hull, W. E., Haubner, R., Spiegelhalder, B., \& Bartsh, H. (2000). The antioxidant/anticancer potential of phenolic compounds isolated from olive oil. European Journal of Cancer, 36, 1235-1247.

Papadopoulus, G., \& Boskow, D. (1991). Antioxidant effect of natural phenols on olive oil. Journal ofAmerican Oil Chemists Society, 68, 669-671.

Shahidi, F., \& Wanasundra, U. N. (1997). Methods of measuring oxidative rancidity in fats and oils. In C. C. Akoh \& D. B. Min (Eds.), Food lipidschemistry, nutrition and biotecnology (pp. 377-396). New York: Marcel Dekker.

Salvador, M. D., Aranda, F., Gomez-Alonso, S.,\&Fregapane, G. (2001). Cornicabra virgin olive oil: A study of five crop seasons. Composition, quality and oxidative stability. Food Chemistry, 74, 267-274.

Stevenson, S. G., Vaisey-Genser, M., \& Eskin, N. A. (1984). Quality control in the use of deep frying oils. Journal of American Oil Chemists Society, 61, 1102-1108.

Tan, C. P., \& Che Man, Y. B. (1999). Differential scanning calorimetric analysis for monitoring the oxidation of heated oils. Food Chemistry, 67, 177184.

Tan, C. P., Che Man, Y. B., Jinap, S., \& Yussof, M. S. A. (2002). Effects of microwave heating on the quality characteristics and thermal properties of RBD palm olein. Innovative Food Science \& Emerging Technologies, 3, 157-163.

Tuck, K. L., \& Hayball, P. J. (2002). Major phenolic compounds in olive oil: Metabolism and health effects. Journal of Nutritional Biochemistry, 13, 636-644.

Vieira, T. M. F. S., \& Regitano d'Arce, M. A. B. (2001). Canola oil thermal oxidation during oven test and microwave heating. LebensmittelWissenschaft und Technologie, 34, 215-221.

Youssif, A. K., Abou Ali, M., \& Bou Idreese, A. (1990). Processing, evaluation and storability of date Jelly. Journal of Food Science and Technology, 27, 264-267.

Youssif, A. K., Alghamdi, A. S., Hamad, A., \& Mustafa, A. I. (1996). Processing and evaluation of a date juice - milk drink. Egyptian Journal of Dairy Science, 24, 277-288.

Youssif, A. K., \& Alghamdi, A. S. (1999). Suitability of some date cultivars for jelly macking. Journal of Food Science and Technology, 36, $515-518$. 